\title{
EXPERIENCE AND ATMOSPHERE OF THE BUILT HERITAGE IN DIGITAL ENVIRONMENT
}

\author{
P. Jouan ${ }^{1}$, P. Sadzot ${ }^{2}$, D. Laboury ${ }^{3}$, P. Hallot ${ }^{1}$ \\ ${ }^{1}$ DIVA, Art Archaeology Heritage University of Liège, 4020 Liège, Belgium - (pjouan, p.hallot)@uliege.be \\ ${ }^{2}$ Alumni of the Faculty of Architecture, University of Liège, 4020 Liège, Belgium - philippe.sadzot@alumni.uliege.be \\ ${ }^{3}$ FNRS Service d'Égyptologie et d'Archéologie égyptienne, University of Liège, 4000 Liège, Belgium - d.laboury@uliege.be
}

KEY WORDS: user experience, atmosphere, virtual environment, sense of place, Egyptology.

\begin{abstract}
:
The digital documentation of heritage places produces accurate 3D restitution of their geometry in a virtual environment and can be related to multiple semantic layers to archive, represent, preserve and transmit the knowledge gathered along their lifecycle. The combination of high-density point clouds with other sources of information advises virtual reconstitutions of historical states of a place's physical realm. The cultural significance of the built heritage lies in the values associated with its tangible and intangible dimensions. Apart from aspects of values related to historical sites' physical attributes, 3D models can support the representation of intangible elements influencing visitors' perception of their Genius Loci and supporting new interpretations about their cultural significance. In this framework, 3D animation, rendering, and simulation technologies allow recreating aspects of a place's atmosphere, like the simulation of lighting conditions and the user's immersive experience of a heritage site into a virtual environment. This paper focuses on the light perception recreated in a funeral chapel of the Theban Tomb environment by considering the strong spiritual dimension in the conception of funeral sites in ancient Egypt during the New Kingdom period (1550-1069 BC). We investigate the potential of 3D simulation and animation technologies to represent hypotheses about original lighting conditions in such sites. The proposed research is based on the case study of Sennefer's tomb chapel, also referred to as TT96A, located on the western bank of the Nile, opposite modern Luxor.
\end{abstract}

\section{INTRODUCTION}

Today's society recognizes the cultural significance of built heritage based on the knowledge gathered throughout its spatial and temporal evolution. The interpretation of multiple information sources and the $3 \mathrm{D}$ reconstitutions of heritage objects and sites allow documenting key episodes of their existence. Such representations aim to inform about and represent the main changes that occurred in their physical realm. Recording techniques such as laser-scanning and photogrammetry now enable accurate $3 \mathrm{D}$ reconstructions of objects geometry in their present state-of-conservation. When high-density point clouds are confronted with historical sources, they constitute a reliable and pertinent source of information to support the hypothesis about previous states of existence of objects. $\mathrm{CAD}$ and $3 \mathrm{D}$ modelling solutions allow representing spatial objects' dimensions. Going deeper into the representation, $3 \mathrm{D}$ animation, rendering, and simulation technologies allow recreating some aspects of a place's atmosphere, like the simulation of lighting conditions and the user's immersive experience of a heritage site into a virtual environment.

The meaning of places and their Genius Loci challenge researchers working in the field of digital cultural heritage, particularly when virtual copies of heritage sites are intended to enable their "experience" by a targeted audience. The main complexity of communicating about the atmosphere of a place through a virtual copy of its physical realm lies in representing all intangible aspects impacting the perception of the built environment. Considering that the atmosphere of a place is a subjective and emotive reaction arising from the physical copresence of a perceiver subject and a perceived object (Kepczynska-Walczak \& Walczak, 2013, 2015; Sørensen, 2015), the question is not anymore to consider whether atmosphere can be fully recreated or represented. Instead, the feasible research question aims at identifying some of the conditions that virtual environment can recreate among the factors allowing the perception of the built environment by individuals, and to what extent they can enable the individual's experience of inaccessible or lost spaces. Thus, one of the specificities of the research relies on bringing under the same umbrella individual reflections on different aspects of the perception scheme. This paper will focus on the light perception recreated in a funeral chappel of the Theban Tomb environment by considering the strong spiritual dimension in the conception of funeral sites in Egypt during the New Kingdom period (1550-1069 BC). We investigate the potential of $3 \mathrm{D}$ simulation and animation technologies to represent hypotheses about original lighting conditions in such sites. The proposed research is based on the case study of Sennefer's tomb, also referred to as TT96A, situated in the Theban Necropolis, located on the western bank of the Nile, opposite of modern Luxor (Bavay \& Laboury, 2012).

The proposed analysis extends the work initially proposed by Sadzot (Sadzot, 2020) during his master thesis. The rest of the paper is structured as follows. The second chapter will outline the context in which the research took place. A brief state-of-the-art section will then overview the genius loci definition and how representations can support the concept. The hypothesis and the research method implemented are proposed in chapter 4 and 5 . The main results are presented in chapter 6. Finally, some conclusions and research perspectives are given at the end of the paper. 


\section{RESEARCH CONTEXT}

\subsection{Archaeological research}

The funerary complex of Sennefer, Theban Tomb (or TT) 96, is part of the research concession kindly granted by the Supreme Council of Antiquities of the Arab Republic of Egypt to the Belgian Archaeological Mission in the Theban Necropolis, a joint project of the Universities of Brussels and Liège, codirected by Laurent Bavay and Dimitri Laboury (Bavay \& Laboury, 2012). It is situated on the southern end of Sheikh Abd el-Gurna hill, in a prominent position in the Theban necropolis, the most important burial place during the ancient Egyptian New Kingdom (ca 1550-1050 BCE), the widest open-air museum of ancient paintings in the world and a highlight in the list of UNESCO worldwide heritage.

In the time of king Amenhotep II (ca 1422-1395 BCE), Sennefer was the governor of ancient Thebes, a liturgic capital of New Kingdom Egypt, the birthplace of the dynasty which initiated this most important period of ancient Egyptian history (Laboury, 2007). He was in charge of the wealthiest economic domain of a temple in the country, the "house of Amun" of Karnak, on the opposite bank of the Nile, and commissioned an exceptional funerary monument to memorialize his identity for future and intended visitors. In addition to an unusually decorated subterranean burial apartment (TT 96B), he ordered a gigantic funerary chapel for his cult and memory to be excavated in the slope of the hill nowadays known as Sheikh Abd el-Gurna. The monument was hewn on a horizontal level almost 30 meters deep into the bedrock, with a 10 meters wide and 4 meters high pillared hall at its rear end (see Figure 1). Bringing sufficient light into this room where a sophisticated iconographic program and statuary groups were displayed was obviously a crucial issue that the ancient architects addressed with the creation of a window on top of the entrance door, inspired by the sanctuary of a famous temple nearby, i.e. the commemorative temple of the female Pharaoh Hatshepsut, the Djeser-djeseru, at Deir el-Bahari, where a yearly festival of the dead used to start.

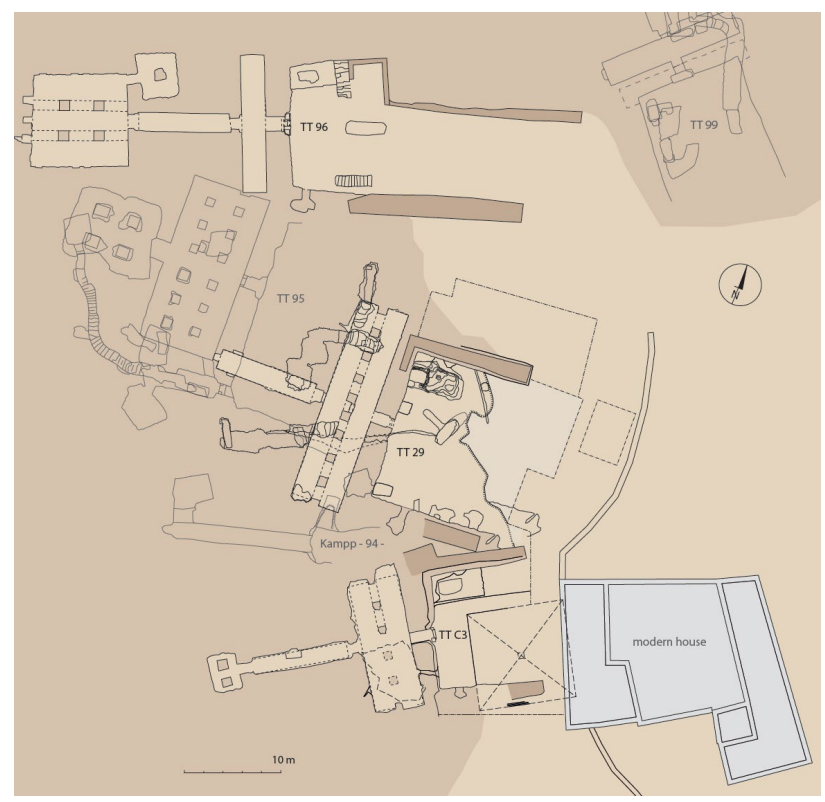

Figure 1. Spatial localization of TT96 and TT29 (from Bavay, Laboury, 2012).
The archaeological study of the monument further revealed structural modifications in order to "templify" the tomb chapel or make it look like a small - private - temple dedicated to Sennefer's commemoration and funerary cult. Besides, art historical analysis of the extensive murals of the monument also showed a significant number of alterations and enhancements, substantiating a remarkable involvement of Sennefer in the design of his commemorative and funerary complex to negotiate and immortalize his identity for future generations through this monumental staging.

The study of the painted decoration of the chapel is likewise considered in the broader context of the Theban painting practices and workshops. This approach developed an original methodology termed "on-site art history" (Bavay, Laboury, 2012). The context of the archaeological mission has also allowed the question of the artist's individuality in the pictorial art of ancient Egypt to be put on a new footing. Everything in the conventions governing Egyptian art tends to make the artist disappear behind his work. Therefore, studying the artists requires an interpretation and knowledge of the pictorial representations present in the monuments studied. In this context, a research project was initiated by Dimitri Laboury and Pierre Hallot to document the entire TT96A funeral chapel.

\subsection{Survey \& 3D restitution}

During the missions held from 2018 to 2020 , a complete survey of the TT96 chapel has been performed. Several acquisition techniques have been combined to offer a comprehensive dataset representing the site with the highest level of detail. A topographical survey of the site was carried out to establish benchmarks to define a consistent coordinate system for all surveys (thanks to the help of Soline Delcros, a member of the MATT mission). This system will be used later in the methodology to gather all the data and validate their quality. The reference points used for this work are salient elements of the epigraphy or marks on the excavated parts of the walls not to damage the supports. Two 3D acquisitions took place as a result of the mission. Firstly a high-definition photogrammetric survey and secondly, a lasergrammetric survey.

\section{STATE OF THE ART}

\subsection{Built heritage: atmosphere and sense of place}

The cultural significance of the built heritage lies in the values associated with its tangible and intangible dimensions. Among the intangible factors influencing the perception of architectural works, three significant concepts can guide the development of virtual representation models :

(1) Choay states that architectural works, in contrast with other types of artistic productions, need to be physically visited. Such experience cannot be replaced by a simple visual observation (Choay, 1999). Considering that "there is more to a space than its physical dimensions" (Shafik Ramzy, 2015), she claims that the perception of a site requires the complete involvement of the subject's senses.

(2) Brandi distinguishes the material reality of a work of art and the actual image intended to be transmitted by the artist (Brandi, 1963). He further indicates that artwork's materiality is not the only medium implemented or used to transmit its image. Additional intermediate elements can affect the perception of the observer and play an important role in this regard. According to him, light and atmosphere are among the most significant "things" impacting the perception of art's image. 
(3) Through the concept of Genius Loci, Norberg-Schulz explains that "a place is a space which has a distinctive character", a particular atmosphere. According to him, the architect's role is to "create meaningful places" (Norberg-Schulz, 1979)

Those elements lead to the development of the notion of the atmosphere within the virtual models of heritage communication. The atmosphere is to be defined as "the common reality of the perceiver and the perceived".

Böhme proposes to liberate the notion of atmosphere from the "object-subject dichotomy" to which it is usually associated, considering atmospheres as both "thinglike" and "subjectlike". He suggests that atmospheres are created by the qualities of things, as elements articulating the thing's presence in space rather than defining aspects of the thing's unity. Considering the emotive dimension of atmospheres, he argues that emotive reactions belong to human subjects since they "are sensed in bodily presence by human beings and this sensing is at the same time a bodily state of being of subjects in space" (Böhme, 1993). Zumthor also discusses the relationship between objects and the atmosphere. He explores this concept through the emotional impact generated on the perceiving subject, in a particular spatial context, by the myriad properties of a thing's materiality and "the orchestration of the movement of people and light" (Sørensen, 2015; Zumthor, 2006). The subjective dimension of atmospheres makes them hardly representable. Sørensen argues that the Genius Loci of a place cannot be recreated, but representations can only "produce its mediation" (Sørensen, 2015). According to Bader, the perceiver, due to its presence in a spatial context, develops feelings and emotions and thus perceives a certain atmosphere, a particular ambience of the space, before experiencing the architectural form itself. In his conceptual representation of the perception phenomena, Bader brings another interesting dimension based on Gibson's theories on object's affordances, which also precedes the perception of a place' spatial qualities (Bader, 2015).

\subsection{D reconstitution and immersive experience}

Information and Communication Technology (ICT) opens new avenues of possibilities to store, organize and share information related to the built heritage involving various stakeholders, regardless of their expertise (Banfi, Brumana, \& Stanga, 2019). $3 \mathrm{D}$ recording techniques for cultural heritage, such as laser scanning and photogrammetry, enable us to create accurate "digital replicas" of the built environment. The generated highdensity point clouds provide experts with a reliable basis for the $3 \mathrm{D}$ virtual reconstruction of a site geometry (Graham, Chow, \& Fai, 2019). In addition, the digital documentation allows the archival and transmission of data related to the history of a place, and 3D models will enable the recreation of historical states of a place's physical realm virtually.

Many papers discuss light and shadow representation in virtual environments (Gutierrez, Sundstedt, Gomez, \& Chalmers, 2008; Kolivand, El Rhalibi, Shahrizal Sunar, \& Saba, 2018; Lassandro, Fioriello, Lepore, \& Zonno, 2020). Others reflect on objects' affordances and their impact on users' experience $(\mathrm{Ch}$ ' $\mathrm{Ng}, \mathrm{Li}$, Cai, \& Leow, 2020), or even on the narratives and storytelling implemented to guide and constraint the visitor's experience (Pybus, Graham, Doherty, Arellano, \& Fai, 2019). Alongside the evolution of 3D modelling techniques and standards, the digital heritage sector witnessed the emergence of alternative technologies to represent and visualize heritage places, allowing a more immersive experience of historic sites through virtual environments. There is a vast literature related to the adoption of virtual, augmented and mixed reality technologies in the fields of archaeology (Almagro Vidal, Ramírez González, \& Clemente
San Román, 2015), (Secci, Beltrame, Manfio, \& Guerra, 2019) and museums (Pedersen, Gale, Mirza-Babaei, \& Reid, 2017; Shehade \& Stylianou-Lambert, 2020). In addition, several authors discussed the potential of such techniques to facilitate the dissemination of knowledge related to the built environment (Caspani, Brumana, Oreni, \& Previtali, 2017; Cipriani, Bertacchi, \& Bertacchi, 2019; Koo, Kim, Kim, Kim, \& Cha, 2019; Pybus et al., 2019). Researchers also demonstrated the added value of immersive technologies to raise awareness about inaccessible heritage sites (Paladini et al., 2019; Trizio et al., 2019). In this perspective and beyond the question of accessibility, the experience proposed in mixed reality environments allows the present observer to explore previous versions of transformed places or even to visit sites that no longer exist (Hallot \& Billen, 2018).

\section{HYPOTHESIS}

In this research, we consider that 3D models are a reliable source to support previous historical states of a site's geometry. On this basis, we postulate that the modelling and the simulation of light experience under a dedicated archaeological reconstruction hypothesis can influence users' experience. The case study of the TT96 is particularly pertinent to explore this issue as it appears that the main door was initially framed by monumental decorated stones and surmounted by a hypaethral opening. Although the presence of such element is quite rare when comparing with other tombs in the Theban necropolis, the system of a skylight in the sanctuary of Amun-Re, located in the temple of Hatchepsut, illustrate the use of an elaborate system to illuminate cult statues in funeral architecture in this era (Figure 2). "The alignment of the Sanctuary oriented towards the sun on the East-West axis of the solar journey was clearly made to permit a precisely controlled influx of sunlight penetrating through the light boxes locating in the walls of the Bark Hall" (Pawlicki, 2017).

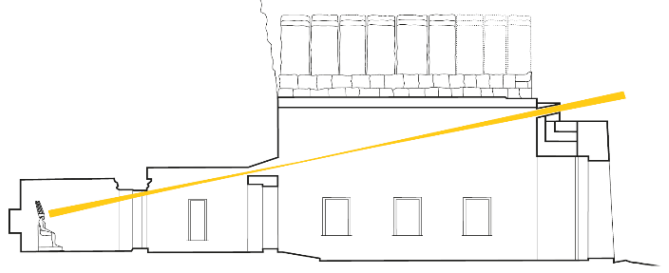

Figure 2. Longitudinal section in Amon Re' sanctuary depicts the luminous flux coming through the elaborated system of skylight to illuminate the cult statue. This illustration was extracted from (Pawlicki, 2017).

Located a few hundred meters away from the Temple of Hatshepsut, the TT96 followed a similar orientation (East-West). In addition, the tomb' spatial configuration and the position and size of the hypaethral suggest that architects also took advantage of the light of the rising sun to illuminate cult statues located in the pillars' hall. Figure 3 shows the actual state of conservation of the front gate (left) and highlights the elements that support such a hypothesis (right). The cavity was probably sealed during previous archaeological campaigns to prevent looting. However, further research was needed to verify the role played by incoming light and its impact on the overall atmosphere of the place. 


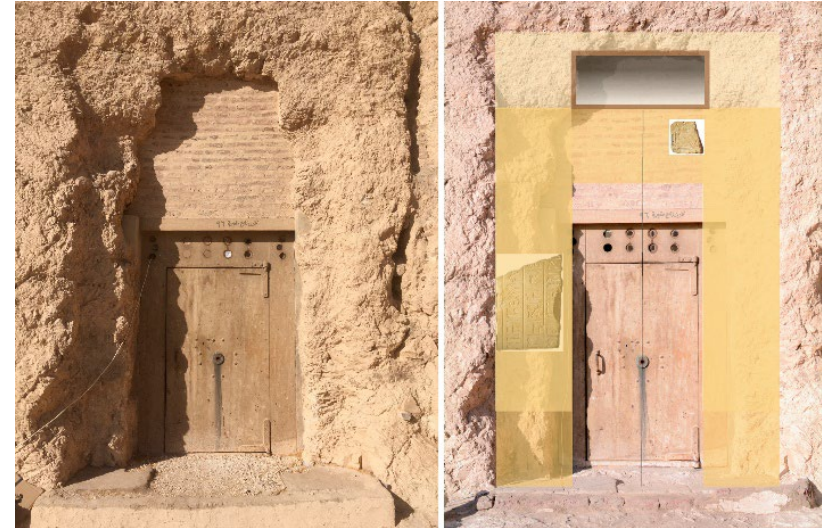

Figure 3. TT96's front door in 2019 (left) and hypothesis about the presence of a hypaethral opening (right)

A first experiment was conducted on a 3D reconstruction of the site based on existing graphic documentation and built-in Sketchup software (Trimble). The model was then approximately located and the topography of the direct surroundings integrated using the geolocation function. Simulations of lighting conditions were then performed using basic 'shadows' functionalities in the same software.

The first results (Figure 4) seemed to confirm the initial hypothesis presuming that the hypaethral opening allowed early morning sun rays to reach the back wall of the pillars hall. The incoming light highlighted the statues of Sennefer and his wife housed in a niche (Laboury, 2007) (see Figure 5). Therefore, it was necessary to verify these initial simulations further. The specific simulation would consider a more precise astronomic alignment, more accurate geolocation and a better geometric representation of the site. The first results were also confronted with the place's current lighting conditions and atmosphere to adjust other representations. The 3D model generated from photogrammetry constituted a reliable and accurate representation of the geometry and appearance of the site and its components. It was therefore used as the basis of this work.

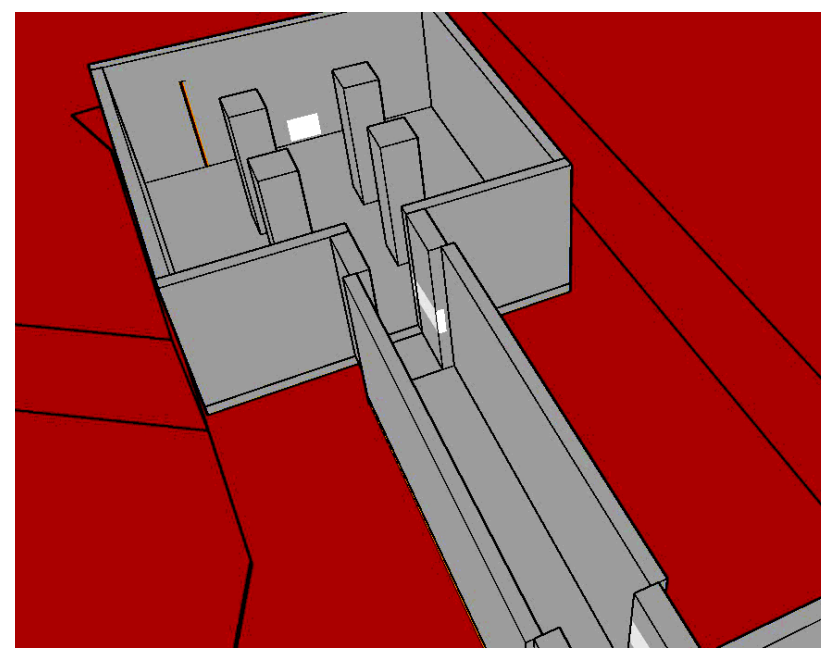

Figure 4. Simulation of lighting condition with the hypaethral opening above the main entrance door.

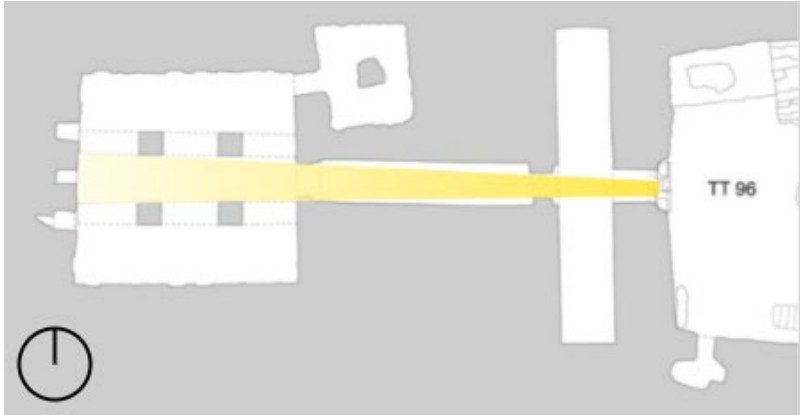

Figure 5. This illustration shows the assumption that early morning sun rays reached the back wall of the pillars' hall at a particular moment of the year.

\section{METHODOLOGY}

\subsection{Survey: tools and methods}

5.1.1 Data acquisition: A photographic cover was set up in the very dark environment of the funeral chapel. Given the cultural significance of wall ornaments in TT96A, photogrammetry was considered the most appropriate method that allows a denser reconstruction of the site's geometry in its current state and a more controlled representation of the colours of the wall paintings. Complete scanning of the site was also achieved to provide a dense point cloud that enables to verify the coherence of the photogrammetric model's geometry.

The acquisition condition and colourimetric controls were defined in collaboration with archaeologists and art historians. The discussions ended up requiring a colour control of the acquired pictures and the need to identify details in a range of 1 $\mathrm{mm}$ at minimum. Based on these requirements, a ground sampling distance of $1 \mathrm{~mm}$ has been fixed. A Nikon D810 digital reflex camera (full-frame sensor, 36.3 MP) was used and equipped with a $35 \mathrm{~mm}$ fixed focal length camera lens (AF-S Nikkor $35 \mathrm{~mm} \mathrm{f} / 1.4$ ). Considering the equipment and complying with the defined objectives in terms of geometric accuracy of the final model, an acquisition distance ranging from 0.5 to 1 meter from surveyed elements was respected. The orientation of the pictures was chosen to be orthogonal to the walls in a first pass. In a second acquisition pass, we took pictures with a significant incidence angle from the walls to ensure high quality in the $3 \mathrm{D}$ reconstruction by limiting a flattering effect of the microtopography of the walls. This method, although very timeconsuming, has been adopted in considering the objective of the documentation, rather oriented towards the production of a $3 \mathrm{D}$ model than 2D orthophotography.

The light sources being very variable, it was chosen to work with three flashes (Nikon SB800) mounted on support accompanying the camera. A customed mobile set-up (Figure 6) was created, placing the camera and the flashes (one on each side and the other on the camera) on a metal bar with (approximate length of 80 $\mathrm{cm})$. This method allowed to work with a relatively high shutter speed and avoid motion blur. Permanent lights were not considered since they require a permanent electrical power supply, which can be problematic in such an environment. By working this way, the exposure of the shots could be controlled, and the influence of residual light sources could be limited as the light of the flashes significantly covers every other light source. Regarding exposure parameters, low sensitivity to light was chosen (ISO 200) to avoid noisy images. The aperture was managed to be fixed for each wall with the better depth of field possible. Additional pictures with a colour chart checker were regularly taken (approximately every 100 photos) to further adjust exposure and white balance. 
The acquisition method ensures similar lighting conditions for all pictures and the coherence of colour reconstruction in the photogrammetric model. The colour validation ensures the global coherence of the model in terms of colourimetric representation.

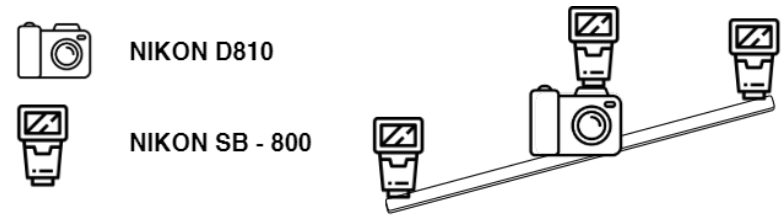

Figure 6. The system used to obtain coherent lighting over all the pictures. The camera equipped with a speedlight flash is placed on the centre of a metal bar, and two other flashes are placed on both extremities.

A control points network was created to constrain the photogrammetric reconstruction and to geo-reference the final model. The points were surveyed via a total station. Because of the vulnerability of the site components, particularly wall ornaments, control points were not materialized with targets. Instead, easily identifiable points on these ornaments were selected (Figure 7), documented and listed to facilitate their identification in Context Capture.

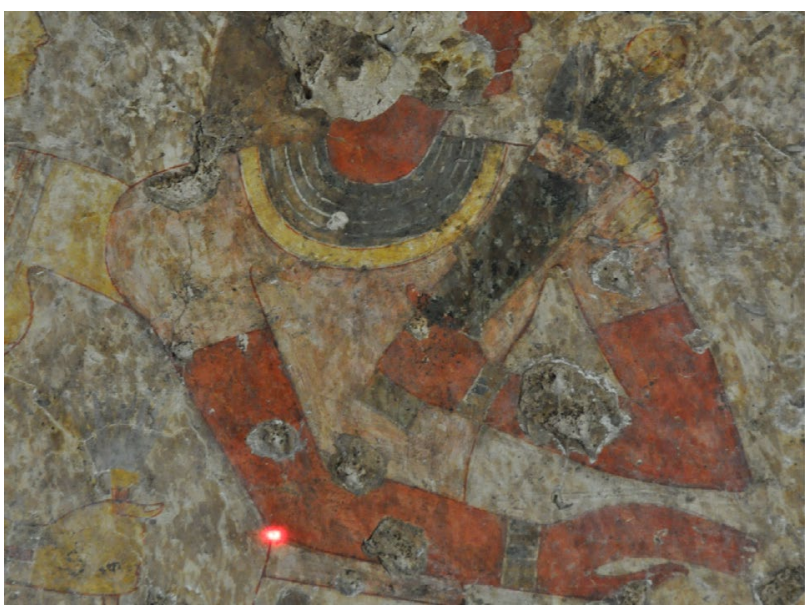

Figure 7. Identification of recognizable points to be surveyed and used as control points.

Data processing and consolidation: A total of 14000 pictures and 150 control points were used in the process. Thanks to Bentley ContextCapture, a complete reconstruction have been performed with a global accuracy of less than $2 \mathrm{~mm}$ for the whole project, which is coherent with the quality of the topographic survey. Bentley enables combining multiple survey data (pictures, topographic survey, laser-scanning data) and allows good control over photogrammetric models' quality. Given the critical amount of data collected, individual spaces were first modelled using multiple blocks in Context Capture and further unified in a single and coherent model. The two first steps of the process involve data integration and verification of camera settings to inform the reconstruction. Next, the aero-triangulation (step 3) allows the alignment of the different groups of photos and generates a first sparse cloud with the tie points used. The final model is then reconstructed (step 4) and the results exported in diverse formats (point clouds, orthophotos, textured mesh) (step 5).
5.1.2 Data exportation: To facilitate historical state reconstruction, the generated textured mesh and coloured point cloud were exported in .obj and .e57 formats. Autodesk Recap and Bentley Pointools software were used for point cloud visualization and Cloud Compare for orthophotos extraction. Regarding the mesh, Blender was adopted for 3D modelling and simulation activities. Several reasons motivated the decision to work with Blender: the software is open-source, allows managing large files, and proposes a large panel of functions helpful in this framework like 3D modelling, texture mapping, and lighting simulation tools.

\subsection{D modelling and simulation}

5.2.1 Raw mesh and simplified models: The mesh generated in Context Capture was too detailed for the purpose of this research as the photogrammetric reconstruction was initially achieved for documentation. Such high polycount mesh in 3D modelling environment challenges the fluidity of navigation and modelling tools and is not necessary for this framework. Therefore, we decided to decimate the mesh resolution to reduce the file size and optimize the workflow. Two solutions with different degrees of simplification were explored. Figure 8 illustrates the complete workflow.

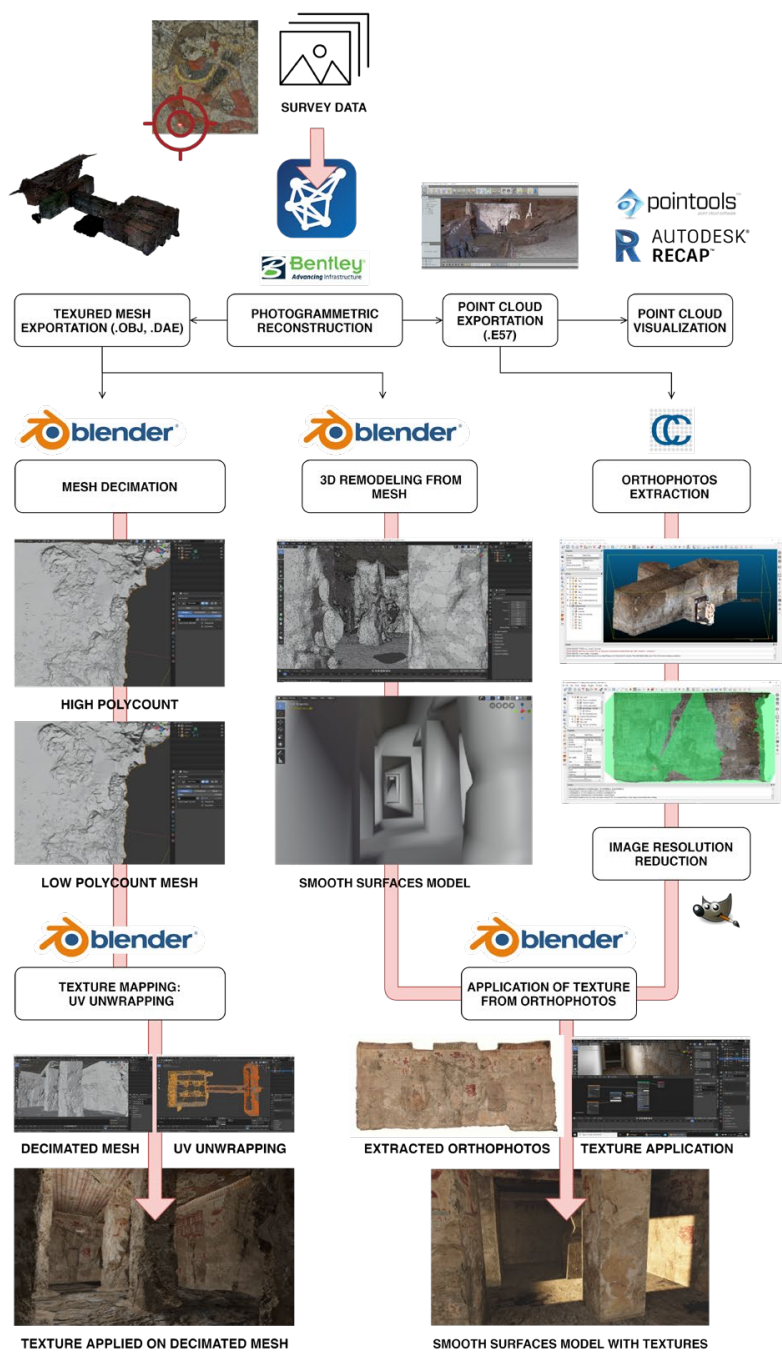

Figure 8. The method implemented for the 3D reconstruction of a previous state of existence of TT96A's geometry and mesh texturing. 
First, the initial model is integrated into Blender to decimate its mesh, reducing its polycount. The 'decimate-collapse' tool was applied with a reduction ratio of 0.05 . This operation reduced the mesh file size and enhanced its handleability while having a low impact on the overall model accuracy. The textures of the base model were then applied to the decimated mesh. Secondly, a "smooth surfaces" model is elaborated by manually remodelling the whole building based on the original mesh. Straight surfaces were first created and further arbitrarily modified with mesh sculpting tools to represent the main deformations observed. This simplified model was then textured using orthophotos extracted from the base model in Cloud Compare and further edited in Gimp. Texture mapping was achieved through the UV Unwrapping function in Blender. In both cases, light absorption and other key parameters of textures were adjusted in Blender. According to fieldwork observations, the texture application is made to correspond better to the actual behaviour of represented materials about natural lighting. The two solutions proposed contrast in their level of geometric accuracy and the fidelity of reconstructed textures regarding the current state of preservation of the site. While the first model is closer to reality, the file size of the second is much lighter. The impact of these choices on light perception in further simulations will be discussed in section 6.

5.2.2 Astronomic alignment: The sun's path near Louxor in 1500 BC: A correct representation of the light condition in the funeral chapel requires locating the light source with good accuracy. We analyzed the sun's path evolution in the last 3500 years. Given the orientation of the tomb's entrance (East), the sunrise is the daytime that influences the most chappel's light condition. This study was achieved through the open-source software "Stellarium", which allows tracking the movements of celestial objects over time.

Among the primary outcomes, this study revealed that, in 2019 , the sun rose 15 minutes earlier than 3500 years ago (Figure 9). Although this difference is not negligible, it should be noted that the total duration of sunshine has not changed. The study achieved in Stellarium allows to adjust lighting simulation parameters in Blender and therefore increase the reliability of the hypothesis that will be made. Initial simulations have been performed at this stage to observe the moments of the year when sunrays actually penetrated the tomb through the hypaethral and when the alignment of the sun and the building allowed sun rays to pass through this opening with the most horizontal and perpendicular angle. For this study, a model integrating the surrounding topography and the simplified mesh of TT96A was used.
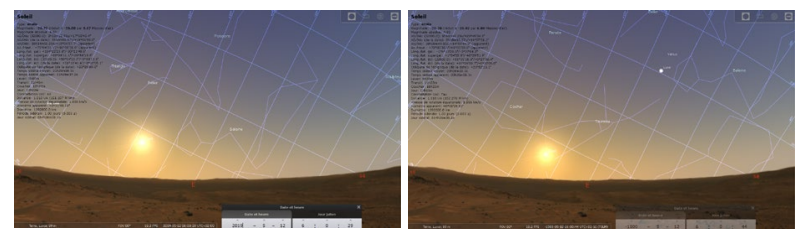

Figure 9. These images show that the sunrise in Luxor on December 5 occurred at 5:20 in 1500 BC (left), and at 5:05 am at the same date in 2019.

The larger exposure of the tomb's entrance to sunrays happens somewhere near August 30. Currently, the first rays penetrated the tomb around 5:30 am with an angle close to the horizon. At that time, a peak of luminosity is abruptly reached. The quantity of direct sunrays remains relatively important until 8:30 am and progressively disappears around $9 \mathrm{am}$. The tomb is thus correctly illuminated by sunlight during approximately 3 hours in the sunniest days of the year. For this research, it was decided to perform further simulations with the estimated position of the sun on August 30,1500 BC, around 6:00 am as sun rays entered the building in the most horizontal and perpendicular (to the front gate) way at this moment. If we consider a short time frame of the building's exposure to direct sunlight, it was considered more pertinent to study its role in visitors' experience at a given time.

\section{RESULTS}

The simulations performed on the two models generated very contrasting results. Overall, the use of the surveyed model (Figure 10) representing all deformations complicates interpretations and understanding of the impact of natural lighting on the atmosphere of the place. The goal is to verify the hypothesis about the impact of natural lighting on the building's original design. Another solution would be to use the surveyed model to model earlier geometry states without representing historical damages. Nonetheless, such an approach should also question the filling of textures for missing parts of the building for which little information is available. Regarding the initial objectives of this research, the results obtained with the simplified mesh are considered more convincing. This model (Figure 11) was therefore used to achieve further simulations.

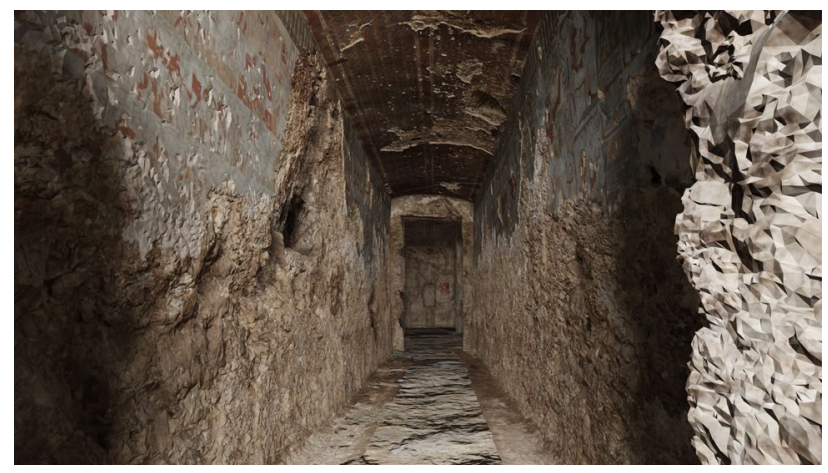

Figure 10. The decimated model in Blender.

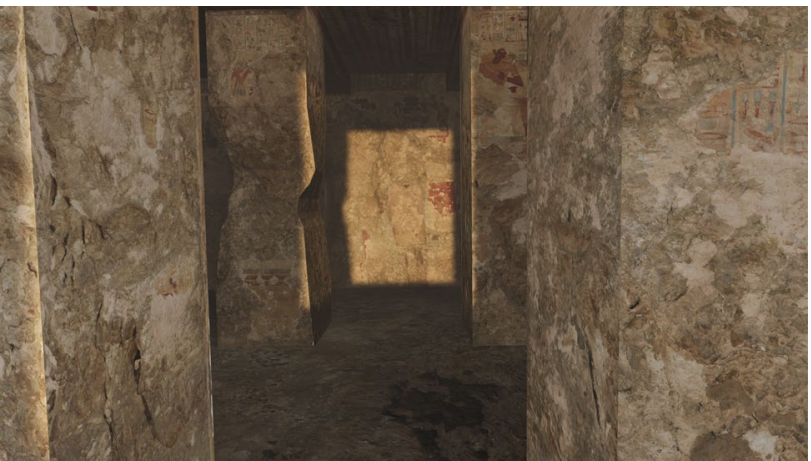

Figure 11. The simplified version (smooth surfaces model) created in Blender.

When looking at the hypothesis of the presence of the entrance door, the hypaethral and two successive doors on the way to the pillars hall, the simulations studied the evolving impact of sun rays on the atmosphere of the place and the visitors' experience. In particular, four main stages in the route from the exterior towards the pillar's hall were tested. The first step simulates the entrance of light when the main entrance door is open, the second open door A \& B, and all doors are opened for the third one. Finally, the last stage simulates the entry of light when a visitor 
reached the pillars' hall, and all the doors were closed behind him. The solely light that penetrates the space is therefore coming from the hypaethral. The four illustrations in Figure 12 schematically represent light diffusion according to the different scenarios along with the visitor's experience. The simulations allowed to reveal the role of natural light in guiding the visitor's route, progressively revealing the wall paintings and enhancing the spiritual dimension of the site.

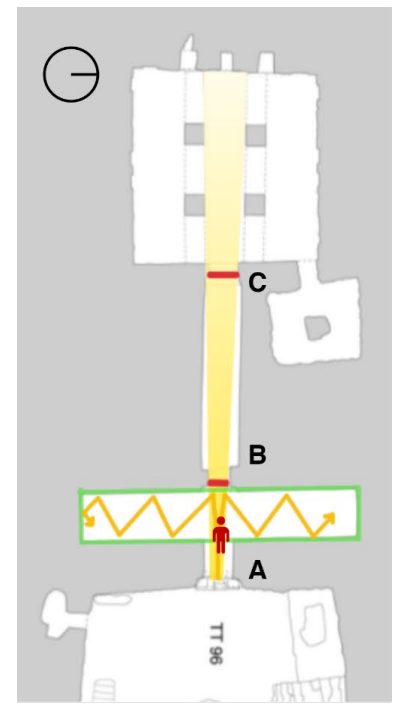

DOOR A OPEN

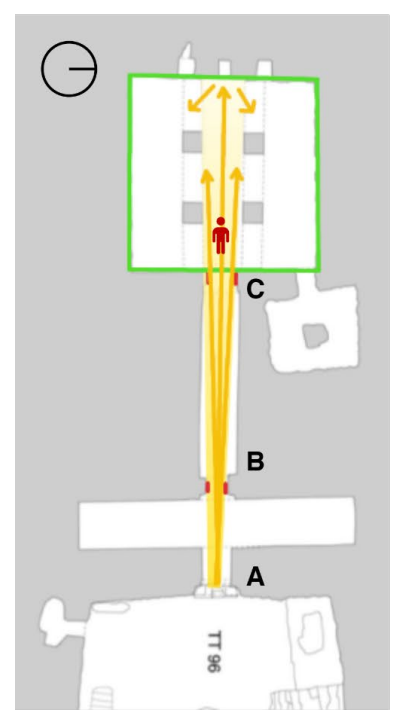

ALL DOORS OPEN

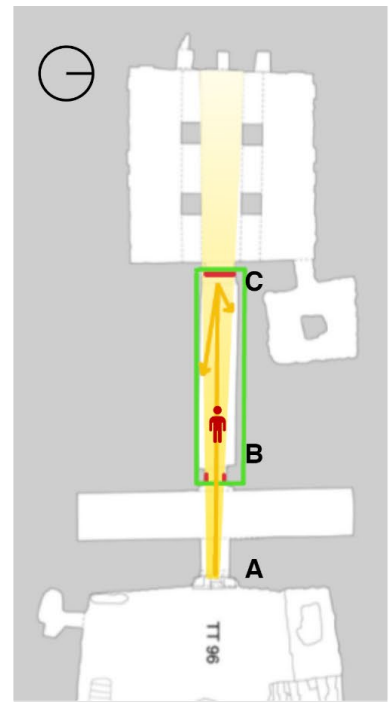

DOOR A \& B OPEN

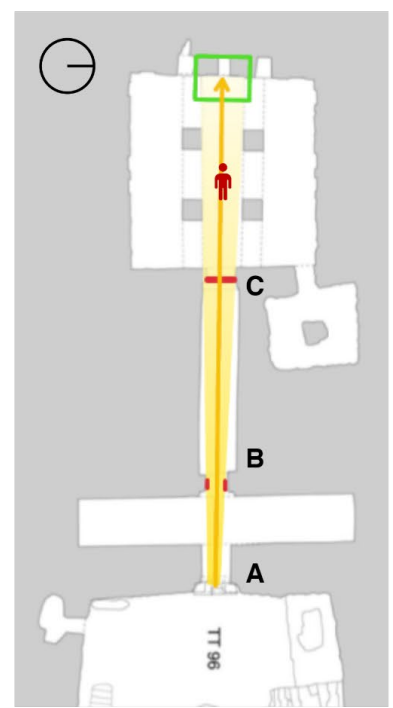

DOOR C CLOSED
Figure 12. These schemes depict four main phases of the visitors' experience and the involving impact of light along his route to the pillars' hall.

The first configuration (Figure 13 - step 1) brings the visitor to the transverse room, which naturally benefits from an intense light near the main entrance. Nevertheless, if the visitor deviates from the east-west axis, the two sides (east and west) of this space are pretty dark. At this stage, it is therefore essential to keep the door closed as it allows to reflect part of the light brought through the hypaethral and illuminate part of the other walls. The second configuration highlights the "ascensional" room, which allows passing progressively from the profane world to the spiritual world (Figure 13 - step 2). In the third configuration, when pushing the last door, the visitor is surprised to discover the immensity of the pillared room. It creates a mysterious and intimidating atmosphere that invites respect and caution because space is not perceived in its entirety. The last configuration is the one where the last door closes behind the visitor's back, and he finds himself in the pillared room with the only light coming from the hypaethral as a point of light at the very back of the chapel. This light comes to strike the place representing Sennefer and his wife, putting the couple in the centre of the glance in the middle of a completely dark space. A sort of nothingness from which only the couple, illuminated by the light, manages to escape, becoming the only point to which one can cling, reassuring the visitor (translated by authors from (Sadzot, 2020)).

Figures 13-15 show the three first stages with door A closed and therefore with the hypaethral as a unique source of natural lighting. Figures 16 to 18 further illustrate the simulations performed from different angles.

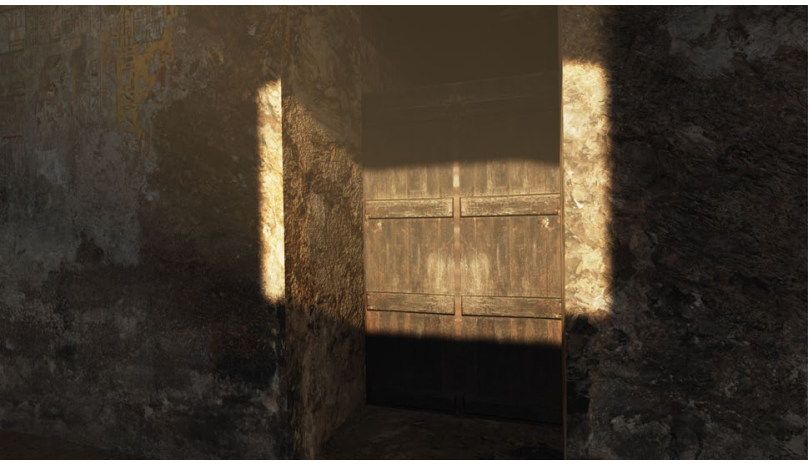

Figure 13. View from the transverse room towards the longitudinal room. Step 1 with the entrance door closed.

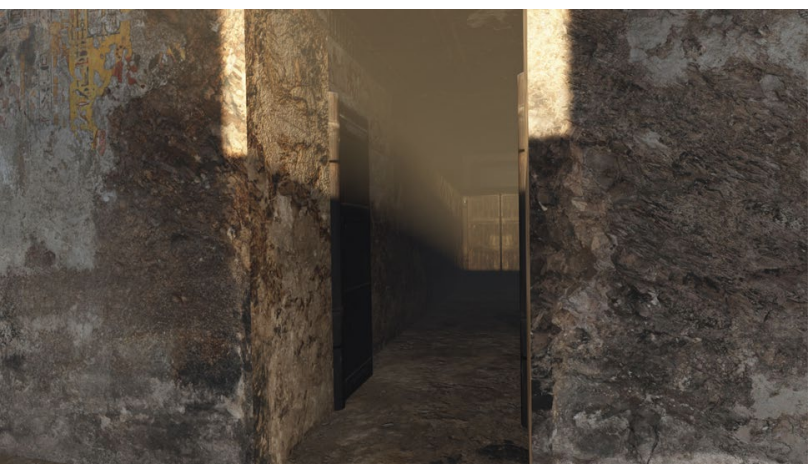

Figure 14. View from the transverse room towards the longitudinal room. Step 2 with the second door open and the entrance door closed. 


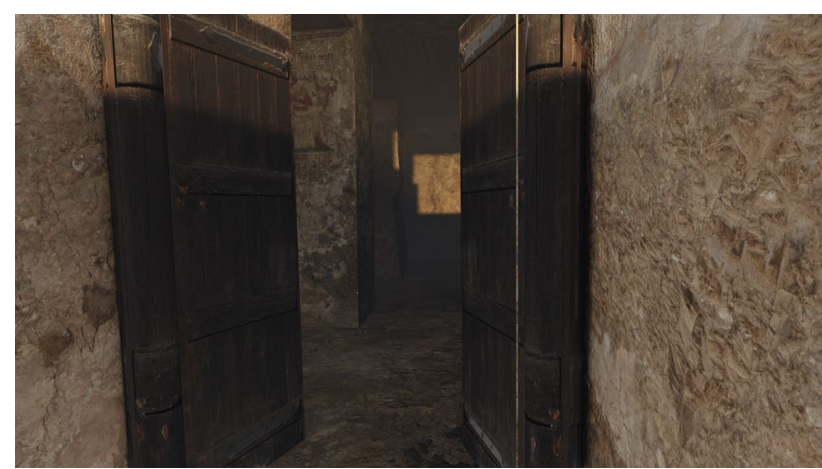

Figure 15. View from the longitudinal room towards the pillars' hall. Step 3 with all doors opened except the front door.

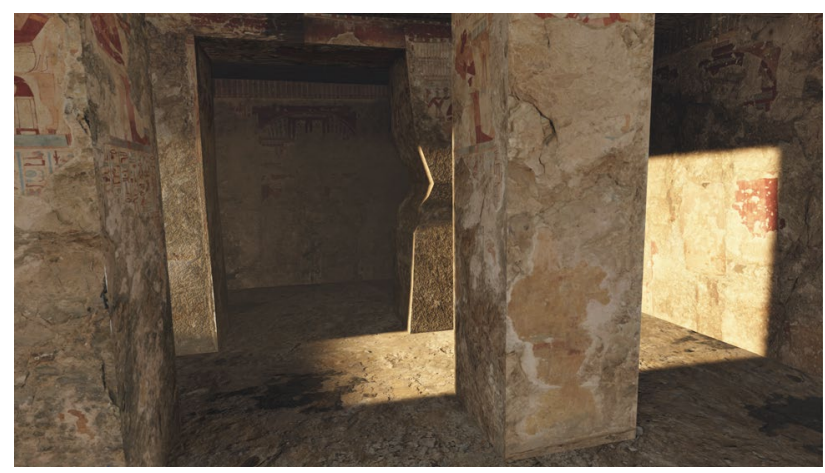

Figure 16. step 3, view from the pillars' hall with doors A, B \& C open.

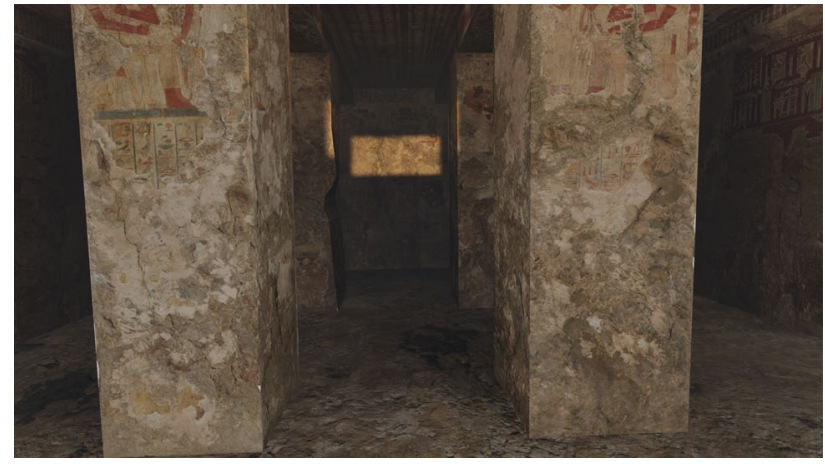

Figure 17. View from the pillars' hall with all doors closed.

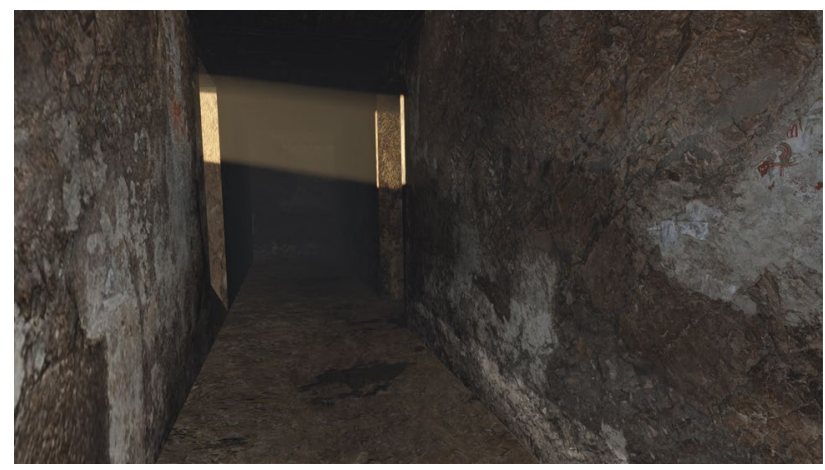

Figure 18. View from the transverse room, looking south. Incoming sunlight from the hypaethral.

\section{CONCLUSIONS}

The proposed study uses precise digital documentation to reconstruct the atmosphere in a burial chapel at Sennefer's tomb. A method for reconstructing several states of the building from the photogrammetric data has been implemented. Using several simplified models, we were able to test various archaeological hypotheses concerning the original openings of the chapel and the doors present in the different rooms. Furthermore, by considering the distinct periods of sunlight, we could highlight characteristic illuminations of certain chapel parts. This approach allows us to understand better the link between the architecture of the building and its scenography.

Furthermore, the approach testifies to the influence of light in the construction of the Theban funerary chapels. Combining geomatic and archaeological approaches allows a better understanding of some archaeological hypotheses and gives tools to test new ones. This type of approach also makes it possible to reconstitute quite faithfully the atmosphere present in this remarkable site that is inaccessible to the public. With the help of digital visualization technologies, it is possible to offer visits closer to the reality of the site by playing on the immersive and sensory aspects of the representation. This work opens many perspectives in terms of the representation of atmospheres on archaeological sites. The capabilities of representing an atmosphere in a virtual environment allow answering archaeological considerations left in question and consider new ones.

\section{REFERENCES}

Almagro Vidal, A., Ramírez González, I., \& Clemente San Román, C. (2015). When the virtual influences reality. The conservation project of the toledo gate in ciudad real (Spain). International Archives of the Photogrammetry, Remote Sensing and Spatial Information Sciences - ISPRS Archives, 40(5W7),

21-27.

https://doi.org/10.5194/isprsarchives-XL-5-W7-21-2015

Bader, A. P. (2015). A model for everyday experience of the built environment: The embodied perception of architecture. Journal of Architecture, 20(2), 244-267. https://doi.org/10.1080/13602365.2015.1026835

Banfi, F., Brumana, R., \& Stanga, C. (2019). A content-based immersive experience of basilica of sant'ambrogio in milan: From 3d survey to virtual reality. ISPRS Annals of the Photogrammetry, Remote Sensing and Spatial Information Sciences, 42(2/W11), 159-166. https://doi.org/10.5194/isprs-Archives-XLII-2-W11-1592019

Bavay, L., \& Laboury, D. (2012). Dans l'entourage de Pharaon. Art et archéologie dans la nécropole thébaine. In PEETERS (Ed.), Ceci n'est pas une pyramide... Un siècle de recherche archéologique belge en Égypte (pp. 62-79).

Böhme, G. (1993). Atmosphere as the fundamental concept of new aesthetics. Thesis Eleven, 36, 113-126. https://doi.org/10.1038/scientificamerican05031919287supp

Brandi, C. (1963). Theory of Restoration. Firenze Nardini Editore.

Caspani, S., Brumana, R., Oreni, D., \& Previtali, M. (2017). Virtual museums as digital storytellers for dissemination of built environment: Possible narratives and outlooks for appealing and rich encounters with the past. International Archives of the Photogrammetry, Remote Sensing and Spatial Information Sciences - ISPRS Archives, 42(2W5), 113-119. https://doi.org/10.5194/isprs-archives-XLII-2W5-113-2017 
Ch'Ng, E., Li, Y., Cai, S., \& Leow, F. T. (2020). The effects of VR environments on the acceptance, experience, and expectations of cultural heritage learning. Journal on Computing and Cultural Heritage, 13(1), 1-21. https://doi.org/10.1145/3352933

Choay, F. (1999). L'allégorie du patrimoine.

workflow for the interactive experience with cultural heritage through reality-based $3 \mathrm{~d}$ models: Cases study in archaeological and urban complexes. ISPRS Annals of the Photogrammetry, Remote Sensing and Spatial Information Sciences, 42(2/W11), 427-434. https://doi.org/10.5194/isprs-Archives-XLII-2-W11-4272019

Graham, K., Chow, L., \& Fai, S. (2019). From BIM to VR: Defining a level of detail to guide virtual reality narratives. Journal of Information Technology in Construction, 24(December), 553-568. https://doi.org/10.36680/J.ITCON.2019.031

Gutierrez, D., Sundstedt, V., Gomez, F., \& Chalmers, A. (2008). Modeling light scattering for virtual heritage. Journal on Computing and Cultural Heritage, 1(2), 1-15. https://doi.org/10.1145/1434763.1434765

Hallot, P., \& Billen, R. (2018). States of knowledge: A basis for a spatio-temporal model of cultural heritage information.

Kepczynska-Walczak, A., \& Walczak, B. M. (2015). Built heritage perception through representation of its atmosphere. Ambiances, https://doi.org/10.4000/ambiances.640

Kolivand, H., El Rhalibi, A., Shahrizal Sunar, M., \& Saba, T. (2018). ReVitAge: Realistic virtual heritage taking shadows and sky illumination into account. Journal of Cultural Heritage, 32(2017), 166-175. https://doi.org/10.1016/j.culher.2018.01.020

Koo, S., Kim, J., Kim, C., Kim, J., \& Cha, H. S. (2019). Development of an augmented reality tour guide for a cultural heritage site. Journal on Computing and Cultural Heritage, 12(4). https://doi.org/10.1145/3317552

Laboury, D. (2007). Sennéfer et Amenemopé, une affaire de famille. Egypte, Afrique \& Orient, 45(Les tombes thébaines 29 et 96), 43-52.

Lassandro, P., Fioriello, C. S., Lepore, M., \& Zonno, M. (2020). , modelling and promoting tangible and intangible values of building heritage with historic flame lighting system. Journal of Cultural Heritage, $\mathrm{xxxx}$ https://doi.org/10.1016/j.culher.2020.09.013

Norberg-Schulz, C. (1979). Genius Loci: Paysage, Ambiance, Architecture (1981st ed.).

Paladini, A., Dhanda, A., Reina Ortiz, M., Weigert, A., Nofal, E., Min, A., (2019). Impact of Virtual Reality Experience on Accessibility of Cultural Heritage. ISPRS Annals of the Photogrammetry, Remote Sensing and Spatial Information Sciences, 42(2/W11), 929-936. https://doi.org/10.5194/isprs-Archives-XLII-2-W11-9292019

Pawlicki, F. (2017). THE MAIN SANCTUARY OF AMUN-RE IN THE TEMPLE OF HATSHEPSUT AT DEIR EL-BAHARI.

Pedersen, I., Gale, N., Mirza-Babaei, P., \& Reid, S. (2017). More than meets the eye: The benefits of augmented reality and holographic displays for digital cultural heritage. Journal on Computing and Cultural Heritage, 10(2). https://doi.org/10.1145/3051480

Pybus, C., Graham, K., Doherty, J., Arellano, N., \& Fai, S. (2019). NEW REALITIES FOR CANADA'S PARLIAMENT: A WORKFLOW FOR PREPARING HERITAGE BIM FOR GAME ENGINES AND VIRTUAL REALITY. International Archives of the Photogrammetry, Remote Sensing and Spatial
Information Sciences - ISPRS Archives, 42(2/W15), 945952. https://doi.org/10.5194/isprs-archives-XLII-2-W15945-2019

Sadzot, P. (2020). Master thesis: Reconstitution de l'atmosphère dans la Tombe de Sennefer avant la condamnation de l'hypèthre". University of Liège.

Secci, M., Beltrame, C., Manfio, S., \& Guerra, F. (2019). Virtual reality in maritime archaeology legacy data for a virtual diving on the shipwreck of the Mercurio (1812). Journal of Cultural Heritage, 40, 169-176. https://doi.org/10.1016/j.culher.2019.05.002

Shafik Ramzy, N. (2015). The Genius Loci At the Great Temple of Abu Simbel: Hermeneutic Reading in the Architectural Language of Ancient Egyptian Temples of Ramses Ii in Nubia. Journal of Ancient History and Archaeology, 2(2). https://doi.org/10.14795/j.v2i2.106

Shehade, M., \& Stylianou-Lambert, T. (2020). Virtual reality in museums: Exploring the experiences of museum professionals. Applied Sciences (Switzerland), 10(11). https://doi.org/10.3390/app10114031

Sørensen, T. F. (2015). More than a feeling: Towards an archaeology of atmosphere. Emotion, Space and Society, 15, 64-73. https://doi.org/10.1016/j.emospa.2013.12.009

Trizio, I., Brusaporci, S., Luigini, A., Ruggieri, A., Basso, A., Maiezza, P., (2019). EXPERIENCING the INACCESSIBLE. A FRAMEWORK for VIRTUAL INTERPRETATION and VISUALIZATION of REMOTE, RISKY or RESTRICTED ACCESS HERITAGE PLACES. International Archives of the Photogrammetry, Remote Sensing and Spatial Information Sciences - ISPRS Archives, 42(2/W15), 11711178. https://doi.org/10.5194/isprs-archives-XLII-2W15-1171-2019 